\title{
Akarsularda Farklı Kaya Parçaları Düzeneklerinde Oksijen Transferinin Deneysel Olarak İncelenmesi
}

\author{
Serhat KÜÇÜKALI ${ }^{*}$ Sevket ÇOKGÖR ${ }^{2}$ \\ ${ }^{1}$ Hacettepe Üniversitesi, İnşaat Mühendisliği Bölümü, Beytepe 06800, Ankara. $\quad$ *®D: https://orcid.org/0000-0002-5867-3270 \\ ${ }^{2}$ İstanbul Teknik Üniversitesi, İnşaat Mühendisliği Bölümü, Maslak, İstanbul. ～(D): https://orcid.org/0000-0002-6698-7456
}

Attf yapmak için: Küçükali, S. \& Çokgör, Ş. (2019). Akarsularda Farklı Kaya Parçaları Düzeneklerinde Oksijen Transferinin Deneysel Olarak İncelenmesi. Anadolu Çev. ve Hay. Dergisi, 4(3), 500-505.

How to cite: Küçükali, S. \& Çokgör, Ş. (2019). An Experimental Investigation of Oxygen Tranfer in Different Boulder Arrangements. Anatolian Env. and Anim. Sciences, 4(3), 500-505.

Öz: Sudaki çözünmüş oksijen (DO), akarsularda suyun kalitesi açısından bakılan en önemli parametrelerden biridir. Sudaki çözünmüş oksijenin akım genelinde veya yersel olarak artışı akarsu habitatı açısından çok önemlidir. Özellikle sanayileşme ve nüfus artışıyla birlikte birçok akarsudaki kirlenme ve katı madde oranı artmıştır. Bu artış serbest yüzeyden suyun derinliğine doğru aktarılan oksijenin miktarının azalmasına yol açmaktadır. Daha önce yapılan çalışmalarda akarsulardaki DO miktarının arttırılması için birçok yapısal çözüm denenmiştir. Bu su yapıları, akarsulardaki çözünmüş oksijen miktarını arttırmalarına rağmen, balık dostu oldukları söylenemez. Bu yapılar akarsulardaki akımın ikiye bölünmesi veya membayla mansap arasındaki ilişkinin kesilmesi gibi ekolojik sorunlara yol açmaktadırlar. Akarsulardaki DO miktarının arttırılması için ekolojik hayatı olumsuz yönde etkilemeden, doğada mevcut bazı düzenekler vardır. Bunlar akarsu içinde yer alan büyük taş parçalarıdır. Bu taş parçaları akım rejiminde önemli etkilere yol açmakta, oksijen transferi için gerekli olan hidrolik sıçrama, çevrinti ve ters akımların oluşması gibi hidrolik koşulları ortaya çıkarmaktadırlar. Bu çalışmada, DO değerleri değişik kaya parçası düzeneklerinin memba ve mansabında ve çevrelerinde yersel olarak ölçülmüştür. Deneyler $0.5 \mathrm{~m}$ genişliğinde, $0.45 \mathrm{~m}$ yüksekliğinde ve $18 \mathrm{~m}$ uzunluğundaki tabanı yatay olan açık kanalda yapılmıştır. Deneyler dört farklı su derinliğinde ve iki farklı kaya parçası düzeneğinde gerçekleştirilmiştir. Ayrıca kaya parçası düzenekleri çevresinde elde edilen DO dağılımları eş oksijen eğrileriyle gösterilmiştir. Bu ölçümler, kaya parçaları çevresinde daha zengin oksijen bulunan olası bölgeleri göstermiştir.

\section{An Experimental Investigation of Oxygen Transfer in Different Boulder Arrangements}

\begin{abstract}
Dissolved oxygen (DO) is one of the most important parameter in streams for environmental issues. Improving the dissolved oxygen in the streams locally or align of the stream is very important for habitat. Especially, after the watersheds get urbanized fine sediment ratio in the most of the streams has been increased. This causes a decrease on the penetration of the oxygen that comes form free surface towards to bottom. In the literature, there were many structural solutions such as weirs to be applied for increasing DO in the stream. Although, they improve the DO values in the streams, they are not fish friendly structures and sometimes causes some another ecological problems such as split out river into two different part and cut the relation between down and upstream. There is more "friendly" and "natural" solution that they could be applied than structural solution mostly based on the natural arrangements in the streams for increasing the DO values locally and align the streams such as replacing boulders in the stream. In the present study, DO values were measured upstream and downstream of the stream under the various flow conditions and efficiency of the system was evaluated for different flow depth and various boulder configurations. Besides that, DO measurements were also conducted around the boulders systemically for determining local DO distribution in measurement section. These measurements clearly indicated possible habitat grown area that had "richer" oxygen around the boulders.
\end{abstract}




\section{GíRiş}

Günümüzde nüfusun ve sanayileşmenin hızlı artışına bağlı olarak doğal kaynaklar hızla tükenmekte ve çevre kirliliği her geçen gün giderek artmaktadır. Bu olumsuz gelişmeler canlı hayatı için vazgeçilmez olan sulak alanların azalmasına ve kirlenmesine yol açmaktadır. İnsan ve çevre sağlı̆̆ açısından suyun kalitesini belirlemeye yarayan en önemli parametrelerden biri su içindeki çözünmüş oksijen konsantrasyonudur (ÇO). Bir sulak alanda gerçekleşen birçok kimyasal, biyolojik ve fiziksel olaylarda sudaki oksijen kullanılmakta ve bu yüzden sudaki oksijen miktarı azalmaktadır. Havadaki oksijenin transferi veya emilmesi, bu kullanılan oksijenin tekrar sağlanması açısından çok önemlidir. Sudaki canlı hayatın devamı için ÇO miktarını 5 mg/L'den büyük olması gerekmektedir. Artüz (2002) Marmara ve boğazlardaki ekolojik değişimini inceleyen çalışmasında, ÇO miktarının $5 \mathrm{mg} / \mathrm{L}$ altına düştüğü 22 metrenin aşağısındaki bölgelerde canlı hayatına rastlanmadığını göstermiştir. Bir açık kanaldaki akım ortamında oluşan birtakım fiziksel değişimlerin sonucunda, havadan suya hava girişi gerçekleşir. Suya hava girişini sağlayan bu fiziksel değişimler şu şekilde özetlenebilir (Wood, 1991): (i) hidrolijik gelişmelere bağlı olarak su seviyesinin alçalıp yükselmesi, (ii) galeri giriş ve çıkışlarında su akımının hava akımını içine çekmesi, (iii) su akım hızının yüksek değerlere ulaşıp düşey yöndeki türbülans çalkantı miktarının büyümesi, (iv) durgun bir suya hareketli bir suyun giriş yapması sonucunda oluşana su jeti, (v) sel rejiminden nehir rejimine geçiş sırasında oluşan hidrolik sıçrama.

$\mathrm{Bu}$ fiziksel değişimlerin yanında, su sıcaklığının ve su üzerindeki hava basıncının değişmesi ÇO miktarında önemli değişimlere yol açar. Suya hava girişine izin veren yukarıda özetlenmiş olan fiziksel değişimler, akım ortamında; çalkantı ve dalgaların oluşmasına, hava girişinin gerçekleştiği yüzeyin (interface) büyümesine, suya hava kabarcıklarının girmesine, ayr1 ayrı olarak veya hepsine birden olanak sağlarlar. Literatürde birçok araştırmacı havasu transferini inceleyen çalı̧̧malar yapmışlardır. Thandaveswara (1974) hidrolik sıçramada meydana gelen hava girişiyle ilgili en kapsamlı çalışmalardan birini yapmıştır. Hidrolik sıçramadaki hava-su akım alanını; türbülans kayma bölgesi, kaynama bölgesi ve köpük emisyon bölgesi olarak üç bölgeye ayırmış ve hava girişinin hava kabarcık girişiyle gerçekleştiği sonucuna varmıştır. Yalnız, yapılmış bu çalı̧̧mada hava konsantrasyonu ve kabarcık boyutu ölçümü eş zamanlı olarak yapılmamış ve hava-su girişim alanı içinde hiçbir bilgi verilmemiş̧ir. Van de Donk (1981) çalı̧̧masında düşey dairesel su jetinde oluşan hava konsantrasyon dağılımını araştırmıştır. Van de Donk (1981) su jetinin, durgun suya dalış yönündeki mesafesinin artmasıyla sudaki hava konsantrasyonun azaldığını belirtmiştir. Butcher ve Covington (1995) Santa Margarita Akarsuyun'daki ÇO miktarının sıcaklıkla olan değişimini incelemişlerdir. Yaptıkları ölçümlerle su sıcaklı̆̆ıyla ÇO konsantrasyonu arasındaki ters orantıyı göstermişlerdir. Su sıcaklığ1 ÇO miktarının değişiminde en önemli parametrelerden bir tanesidir ve bu konuda geliştirilen amprik formüllerde genelde referans sıcakl $\breve{g ̆}_{1} \quad 20^{\circ} \mathrm{C}$ alınmıştır.

Bir hidrolik yapıdaki oksijen transfer verimini tahmin edebilmek için araştırmacılar tarafindan yapılmış birçok model deneylerin sonucunda amprik formüller geliştirilmiştir. Avery ve Novak (1978) geliştirdikleri amprik formülde, hidrolik mühendisliğinde yaygın olarak kullanılan Froude $\left(\mathrm{q}_{\mathrm{w}} / \sqrt{g \cdot d_{1}{ }^{3}}\right)$ ve Reynolds $\left(\mathrm{q}_{\mathrm{w}} / \mathrm{v}\right)$ gibi boyutsuz katsayılarının artmasıyla oksijen transfer veriminin arttığı sonucuna ulaşmışlardır. Boyutsuz katsayılardaki; $\mathrm{q}_{\mathrm{w}}$, birim genişlikteki debi, $\mathrm{d}_{1}$, hidrolik sıçramadan önceki su yüksekliği, g, yerçekimi ivmesi ve $v$ ise suyun kinematik viskozitesidir. Literatürde dolu savaklar, savaklar, enerji kırıcılar, galeriler gibi farklı hidrolik yapılar için geliştirilmiş birçok amprik formül bulunmaktadır. Gulliver v.d (1998) hidrolik yapılardaki muhtemel hava giriş yerlerini göstermiş̧lerdir. Çalışmalarında hidrolik yapılarda suya hava girişi için gerekli hidrolik koşulların sağlandığı bölgelerde hava girişi gerçekleştiğini belirtmiş̧lerdir. Chanson (1994) basamaklı yapılar üzerindeki hava-su transferini inceleyen çalışmalarında; basamaklar üzerindeki hava-su transferinin basamaklar üzerindeki akımın rejimiyle değiştiğinin, basamaklı dolu savağın düz bir dolu savağa göre oksijen transferi yönünden daha verimli olduğunu göstermiştir.

Yapılan bu çalışmada bir açık kanal içersine farkı düzenekte küpler yerleştirilerek akım koşulları değiştirilmiştir ve akım ortamına küplerin yerleştirilmesiyle akım alanında dalgalanmalar, çalkantılar ve hidrolik sıçrama oluşturulmuştur. Akım koşullarındaki bu değişimin sudaki oksijen transferine nasıl bir etkisi olduğu küpler çevresinde yapılan ÇO ölçümleriyle araştırılmıştır. Ayrıca deneylerde dört farklı su derinliğinde çalışılmış ve su derinliği değişiminden oksijen transfer veriminin nasıl etkilendiği analiz edilmişsir.

\section{HAVA-SU GAZ TRANSFERİ}

Bir kimyasal maddenin girişim normali boyunca $\mathrm{x}$ doğrultusundaki kütle transfer oranı Fick kanunuyla hesaplanır (Streeter ve Wylie, 1981). Fick kanununa göre, madde taşınımı konsantrasyonun büyük olan konumdan küçük olan konuma doğrudur. Bu ifade;

$$
\frac{d}{d t} \mathbf{M}_{\mathrm{gaz}} \boldsymbol{\alpha} \mathbf{D}_{\mathrm{gaz}}\left(\frac{d}{d x} \mathbf{C}_{\mathrm{gaz}}\right)
$$


Burada; $\mathrm{M}_{\mathrm{gaz}}$, gazın kütlesi, $\mathrm{D}_{\mathrm{gaz}}$, moleküler difüzyon katsayısı, $\mathrm{C}_{\mathrm{gaz}}$, sıvı içindeki çözünmüş kimyasal madde konsantrasyonudur. $\mathrm{Bu}$ ifade sudaki çözünmüş kimyasal bir madde için yazılacak olursa;

$$
\frac{d}{d t} \mathrm{M}_{\mathrm{gaz}}=\mathrm{K} \mathrm{M} \cdot \mathrm{A}\left(\frac{\mathrm{P}_{\mathrm{gaz}}}{\mathrm{H}_{\mathrm{gaz}}}-\mathrm{C}_{\mathrm{gaz}}\right)
$$

Burada; $\mathrm{K}_{\mathrm{M}}$, kütle transfer katsayısı, A, gaz-sıvı girişim alanı, $\mathrm{P}_{\mathrm{gaz}}$, gazın havadaki kısmi basıncı, $\mathrm{H}_{\mathrm{gaz}}$, Henry katsayısıdır. Henry kanuna göre sabit sıcaklıkta herhangi bir gazın çözüneceği sıvıdaki hacminin ağırlığı, gazın sıvı üzerindeki basıncıyla doğru orantılıdır:

$\mathrm{H}_{\mathrm{gaz}}$, sicaklığın, tuzluluğun, su yüzü şeklinin bir fonksiyonudur. $\mathrm{H}_{\mathrm{gaz}}$ basınç değişimlerinde sabit kalmaz. 2 ifadesi hava gaz karışımının toplam hacmine bölünecek olursa: ifade;

$$
\frac{d}{d t} \mathrm{C}_{\mathrm{gaz}}=\underline{\mathrm{K}_{\mathrm{L}} \mathrm{a}}\left(\mathrm{C}_{\mathrm{S}}-\underline{\mathrm{Cgaz}}\right)
$$

şeklini alır. Burada; a, oksijen transferinin gerçekleştiği yüzey alanının hacme olan oranıdır, $\mathrm{K}_{\mathrm{L}}$, Sıv1 kütle transfer katsayısıdır ve yaklaşık olarak $\mathrm{K}_{\mathrm{M}}$ 'ye eşit olarak alınabilir $\left(\mathrm{K}_{\mathrm{M}} \cong \mathrm{K}_{\mathrm{L}}\right)$ (Chanson 1995). Kuvvetli türbülans karışımlarında $\mathrm{K}_{\mathrm{L}}$ katsayısının değeri büyümektedir. Ayrıca büyük miktarda hava kabarcığının girişi, toplam kabarcık yüzey alanına bağlı olarak hava-su giriş alanında artışa neden olmaktadır. $\mathrm{K}_{\mathrm{L}}$ ve a terimleri zamanla değişir ve hesaplanması oldukça zordur. $\mathrm{C}_{S}$ ifadesinin zamanla değişmediği kabülü yapılıp 3 ifadesi bir açık kanaldaki hidrolik yapıdaki kontrol hacminde, membayla mansap arasında integre edilecek olursa (Gulliver v.d 1998) ;

$$
\underline{\mathrm{r}}=\frac{C_{S}-C_{U}}{C_{S}-C_{D}}=\exp \left[\int_{\text {memba }}^{\text {mansap }} K_{L} a \cdot d t\right]
$$

ifadesi elde edilir. İfade de; r, oksijen kazanım katsayıs1, $\mathrm{C}_{\mathrm{D}}$, mansap bölgesindeki oksijen konsantrasyonu, $\mathrm{C}_{\mathrm{U}}$, memba bölgesindeki oksijen konsantrasyonu, $\mathrm{C}_{\mathrm{S}}$, havadaki oksijen konsantrasyonudur. DO değişimini ölçmeye yarayan diğger bir katsayı E'dir.

$$
\mathrm{E}=\frac{C_{D}-C_{U}}{C_{S}-C_{U}}=1-\frac{1}{r}
$$

Eğer ; $\mathrm{E}=0$ ise oksijen kazanımı gerçekleşmemiş, $\mathrm{E}=1$ ise oksijen kazanımı en büyük değerine ulaşmıştır. Oksijen transfer verim katsayısı (E) su sıcaklığı değişiminden etkilenir. Hidrolik yapılarda en çok kullanılan sıcaklık düzeltme faktörlerinden biri Gamerson v.d (1958) geliştirdikleri formüldür. Bu ifade;

$$
1-E_{i}=\left(1-E_{T}\right)^{1 / f}
$$

İfadede, $\mathrm{E}_{\mathrm{T}}$ ölçüm yapılan sıcaklıktaki, $\mathrm{E}_{\mathrm{i}}$ istenilen sıcaklıktaki oksijen transfer verim katsayısıdır. f ise sıcaklık değişimini gösteren çeşitli değişkenlerin etkisinin dikkate alınmasıyla hesaplanan bir katsayıdır.

\section{MATERYAL VE METOT}

Açık kanallarda oksijen transferini incelemek için laboratuarda deneyler yapılmıştır. İ.T.Ü Hidrolik Laboratuarı'nda yapılan bu deneylerde bir açık kanaldaki su akımı içine yerleştirilen değişik boyutlardaki küplerin etrafinda oksijen konsantrasyonu, hız dağılımı ve su yüzü ölçümleri yapılmıştır. Deneylerde ölçüm ortamına yerleştirilmiş küplerin yarattığı değişik sınır koşullarında, su derinliğin etkisi ile oluşan değişik akım şartlarında, küplerin memba ve mansabında oksijen miktarındaki değişim ve küplerin etrafındaki dağılım belirlenmiştir.

Deneyler Şekil 1.a'da görülen $12.35 \mathrm{~m}$ uzunluğundaki kanalda yapılmıştır. Kanalın genişliği $50 \mathrm{~cm}$, yüksekliği $45 \mathrm{~cm}$ ve tabanı yataydır. Kanalın yan cidarları camdan yapılmıştır. Kanalda farklı su derinliklerinde düşey hız dağılımı profillerini elde etmek için bir adet mikro muline kullanılmıştır. Her bir seri için elde edilen düşey hız dağılımlarından suyun ortalama hızı ( $U_{\text {ort }}$ ) elde edilmiştir. Akımın debisi, kanalın başında yer alan üçgen savakta yapılan ölçümlerle hesaplanmıştır. Kanalda oksijen ölçümleri için WTW OXİ 539 oksijen metre aleti kullanılmıştır ve oksijen ölçüm bölgesi açık kanaldaki üçgen savağın $610 \mathrm{~cm}$ mansap tarafindadır. Ayrıca suyun ve havanın sıcaklık ölçümleri oksijenmetre aletiyle yapılmıştır. Yersel oksijen ölçümü için 44 noktadan oluşan bir ağ oluşturulmuştur (Şekil 1.b). Taş düzenekleri ağın başlangıç noktasından $10 \mathrm{~cm}$ mansaba kanalın yan cidarlarına bitişik halde yerleştirilmiştir. Ölçüm bölgesinin başlangıcının $50 \mathrm{~cm}$ memba tarafina kanalın orta noktasında ve su derinliğinin yarısında $\mathrm{C}_{\mathrm{U}}$, ölçüm bölgesinin bitişinin $50 \mathrm{~cm}$ mansap tarafında kanalın orta noktasında $C_{D}$ ölçümleri yapılmıştır. $C_{S}$ ölçümleri ise suyun dışında havada yapılmıştır.

Deneylerde 5, 10, 15 ve $20 \mathrm{~cm}$ olmak üzere dört farklı su derinliğinde çalışılmıştır. Yalnız küçük küpün olduğu 15 ve $20 \mathrm{~cm}$ su derinliklerindeki düzeneklerde, küçük küp akım alanında sabit kalmadığı için ÇO ölçümleri yapılmamıştır. Deneylerde ÇO ölçümleri kanal tabanının 2 cm yukarısında yapılmıştır. Akım koşulları ve deney sonuçları Tablo.1'de verilmiştir. Tablo.1'de verilen $E_{\text {mak }}$ ve $r_{\text {mak }}, C_{D}$ yerine o seride ölçülen en yüksek ÇO miktarının alınmasıyla hesaplanmıştır. 


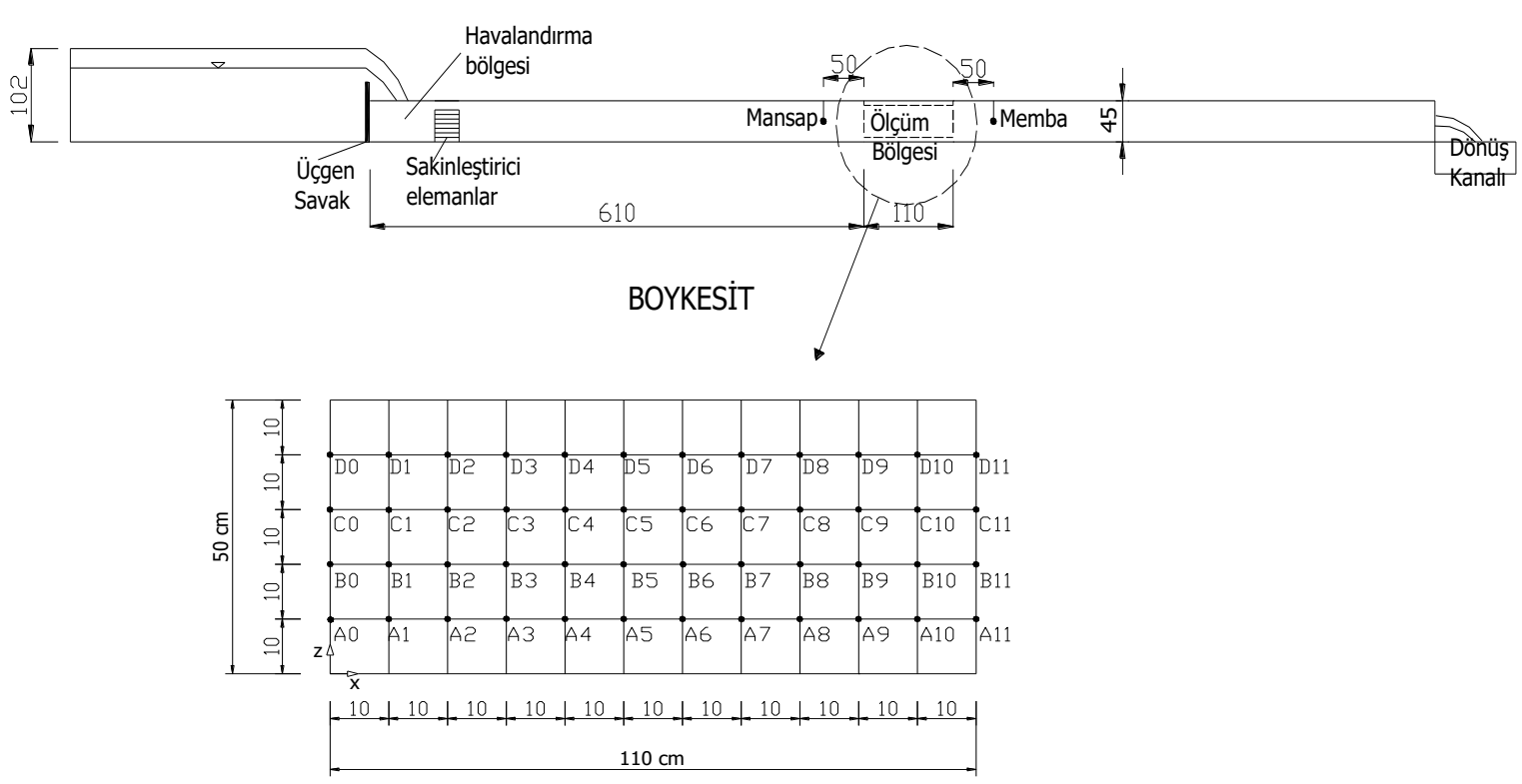

Şekil 1. Deney kanalı ve oluşturulmuş ölçüm ağı.

\section{BULGULAR}

Yapılan deneylerde akım ortamında oluşturulmuş fiziksel değişimlerle, yersel olarak oksijen kazanımı ve akım genelinde oksijen kazanmış bölgelerin oluşturulması hedeflenmektedir. Deneylerde gerçek kaya parçalarını benzeştirmek için 15 ve $6 \mathrm{~cm}$ olmak üzere beton bloklarla yapılmış iki farklı boyutta küp kullanılmıştır. Tablo 1 incelendiğinde $20 \mathrm{~cm}$ 'e yakın su derinliklerinin olduğu düzeneklerde oksijen transferinin gerçekleşmediği görülmektedir. $\mathrm{Bu}$ durum, $20 \mathrm{~cm}$ su derinliğinde küplerin akım şartlarında önemli bir değişme yol açmaması olarak açılanabilir. $10 \mathrm{~cm}$ akım derinliğindeki düzeneklerde oluşan ÇO dağılımları Şekil 1, Şekil 2 ve Şekil 3 ’te gösterilmiştir.

Tablo 1. Deneylerdeki akım koşulları ve deney sonuçları.

\begin{tabular}{|c|c|c|c|c|c|c|c|c|c|c|c|c|c|c|}
\hline \multicolumn{2}{|c|}{ Seri no Küp düzenekleri } & \multirow{2}{*}{$\begin{array}{c}\mathrm{h} \\
(\mathrm{cm})\end{array}$} & \multirow{2}{*}{$\begin{array}{c}\begin{array}{c}\mathrm{q} \\
\left(\mathrm{m}^{2} / \mathrm{s}\right)\end{array} \\
0.0052\end{array}$} & \multirow{2}{*}{$\begin{array}{c}\begin{array}{c}\mathrm{U}_{\text {ort }} \\
(\mathrm{cm} / \mathrm{s})\end{array} \\
9.35\end{array}$} & \multirow{2}{*}{$\begin{array}{c}\mathrm{T}_{\text {hava }} \\
\left({ }^{\circ} \mathrm{C}\right)\end{array}$} & \multirow{2}{*}{$\begin{array}{c}\mathrm{T}_{\mathrm{su}} \\
\left({ }^{\circ} \mathrm{C}\right)\end{array}$} & \multirow{2}{*}{$\begin{array}{c}\begin{array}{c}\mathrm{CS}_{\mathrm{S}} \\
(\mathrm{mg} / \mathrm{L})\end{array} \\
8.15\end{array}$} & \multirow{2}{*}{$\frac{\begin{array}{c}\mathrm{C}_{\mathrm{U}} \\
(\mathrm{mg} / \mathrm{L})\end{array}}{7.54}$} & \multirow{2}{*}{$\frac{\begin{array}{c}\mathrm{C}_{\mathrm{D}} \\
(\mathrm{mg} / \mathrm{L})\end{array}}{7.7}$} & \multirow{2}{*}{$\begin{array}{c}\begin{array}{c}\mathrm{C}_{\max } \\
(\mathrm{mg} / \mathrm{L})\end{array} \\
7.73\end{array}$} & \multirow{2}{*}{$\begin{array}{c}\mathrm{E} \\
0.26\end{array}$} & \multirow{2}{*}{$\begin{array}{l}E_{\max } \\
0.31\end{array}$} & \multirow{2}{*}{$\begin{array}{c}\mathrm{r} \\
1.36\end{array}$} & \multirow{2}{*}{$\begin{array}{l}r_{\text {max }} \\
1.45\end{array}$} \\
\hline & Tek küp (15x15x15cm) & & & & & & & & & & & & & \\
\hline & $(15 \times 15 \times 15 \mathrm{~cm})$ & 9.26 & 0.026 & 28.08 & 25.8 & 25 & 8.11 & 7.67 & 7.69 & 7.77 & 0.05 & 0.23 & 1.05 & 0.05 \\
\hline & Tek küp $(15 \times 15 x 15 \mathrm{~cm})$ & 15.7 & 0.03 & 18.90 & 26 & 25 & 8.35 & 8.09 & 8.12 & 8.15 & 0.11 & 0.23 & 1.13 & 1.30 \\
\hline & Tek k & 19.9 & 0.041 & 20.64 & 26.6 & 26 & 8.24 & 7.97 & 7.97 & 7.97 & 0.00 & 0.00 & 1.00 & 1.00 \\
\hline & İki küp (15x15x15cm) & 5.24 & 0.005 & 9.16 & 25.1 & 25 & 7.98 & 7.45 & 7.62 & 7.67 & 0.32 & 0.42 & 1.47 & 1.71 \\
\hline & İki ki & 10.1 & 0.013 & 12.72 & 25 & 26 & 7.94 & 7.56 & 7.62 & 7.85 & 0.16 & 0.76 & 1.19 & 4.22 \\
\hline & $15 \times 15 \mathrm{~cm})$ & 15.1 & 0.026 & 17.26 & 25.3 & 26 & 8.16 & 7.81 & 7.84 & 8.01 & 0.09 & 0.57 & 1.09 & 2.33 \\
\hline$\delta$ & $\begin{array}{l}\text { İki küp }(15 \times 15 \times 15 \mathrm{~cm}) \\
\text { İki küp }\end{array}$ & 18.4 & 0.046 & 25.16 & 25.3 & 26 & 8.17 & 7.89 & 7.89 & 7.89 & 0.00 & 0.00 & 1.00 & 1.00 \\
\hline 9 & $\begin{array}{l}(15 \times 15 \times 15 \mathrm{~cm}) \text { ve }(6.5 \times 6.5 \times 6.5 \mathrm{~cm}) \\
\text { İki küp }\end{array}$ & 5.86 & 0.003 & 5.80 & 26.2 & 26 & 7.8 & 7.52 & 7.64 & 7.68 & 0.43 & 0.57 & 1.75 & 2.33 \\
\hline 10 & $(15 \times 15 \times 15 \mathrm{~cm})$ ve $(6.5 \times 6.5 \times 6.5) \mathrm{cm}$ & 9.86 & 0.012 & 12.58 & 25.8 & 26 & 7.8 & 7.6 & 7.66 & 7.69 & 0.30 & 0.45 & 1.43 & 1.82 \\
\hline
\end{tabular}

Akım ortamında tek küp varken $\mathrm{h}=10 \mathrm{~cm}$ 'de etkin çeviriler, dalgalanmalar oluşmuştur ve bu bölgelerde oksijen kazanımı sağlanmıştır (Şekil 1). Çeviriler etkisini B2 noktasında göstermeye başlamış, buna bağlı olarak B2, B3, C2, C3 noktalarına çevirilerin artışına bağlı olarak ÇO miktarında bir artış olmuştur. Taşın arkasındaki bölgede ise ölü bölge (akıma katılmayan) oluşmuş ve A aksı boyunca ÇO miktarında membada referans noktada ölçülen değere göre belirgin düşüş gözlenmiştir. Akım genelinde \%21'lik, yersel olarak \%43'lük bir oksijen kazanımı sağlanmıştır.

$\mathrm{Bu}$ düzenekte akım taşların arasından geçerken hidrolik sıçrama oluşmuştur. Hidrolik sıçramanın görüldüğü B2 ve C2 noktalarında oksijen kazanımı maksimum olarak gözlenmiştir. Literatürden görüldüğü üzere, hidrolik sıçrama sırasında türbülans miktarında büyüme ve suya hava kabarcık girişi olur. Tek küpte olduğu gibi taşın arkasındaki A noktasında bir ölü bölge oluşmamıştır. 6-7 aksları arasında suyun altından üstüne doğru hava kabarcıklarının hızlı bir şekilde hareket ettiği gözlenmiştir. Akım genelinde \%16, yersel olarak ise \%76'llk bir oksijen kazanımı sağlanmıştır.

$\mathrm{Bu}$ düzenekte büyük küpün $\left(15^{*} 15^{*} 15\right)$ iz bölgesinde akıma katılmayan ölü bölge oluşurken, küçük küpte böyle bir oluşum gözlenmemiştir. Küçük küp suya batmış durumdadır. Taşların etkisiyle suda oluşan çeviriler ve çalkantılar, hava-su transferinin gerçekleşmesini sağlamışlardır. Büyük küpün arkasındaki $\mathrm{A}$ aksında suda 
oksijen miktarında azalma olurken, küçük küp oksijenin B, C, D akslarında üniform bir şekilde yayılım göstermesini sağlamıştır. Akım genelinde \%30, yersel olarak ise \%45'lik bir oksijen kazanımı olmuştur.

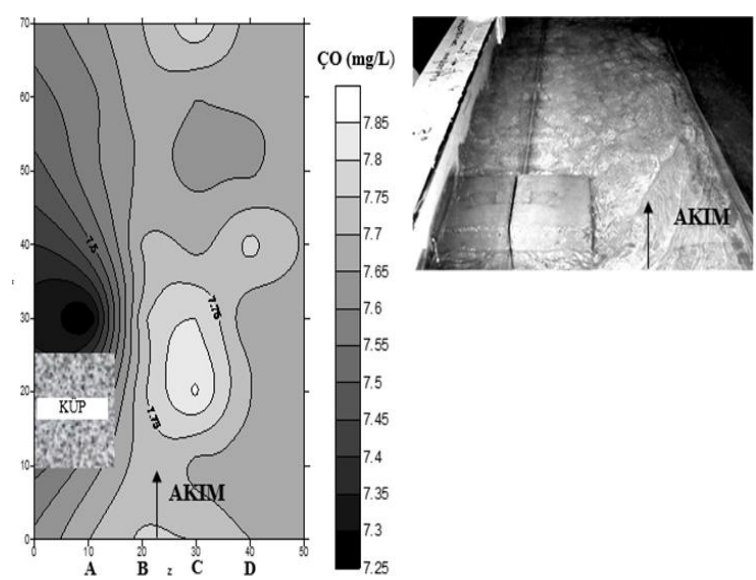

Şekil 2. Tek küp düzeneğindeki ÇO dağılımı $(\mathrm{h}=10 \mathrm{~cm}$, Küp boyutu $=15 * 15 * 15$ ).
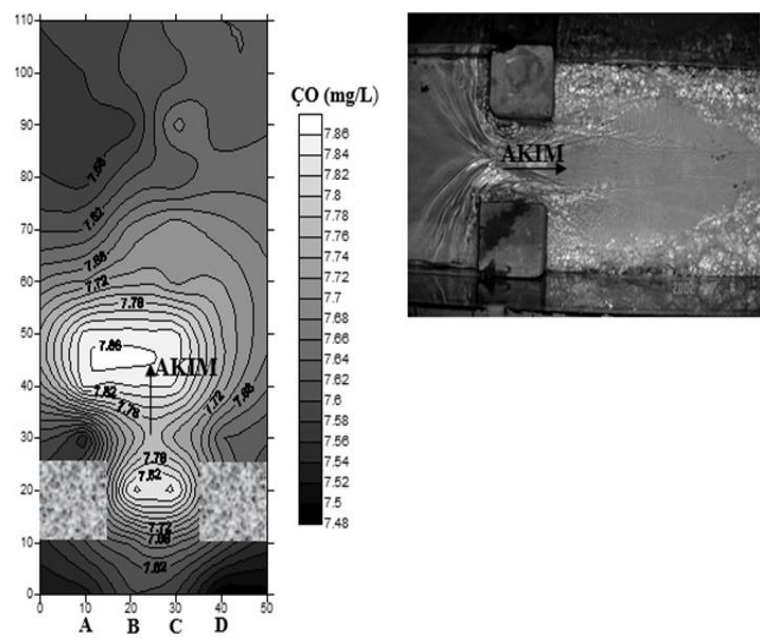

Şekil 3. İki küp düzeneğindeki ÇO dağılımı $(\mathrm{h}=10 \mathrm{~cm}$, Küp boyutları $=15 * 15 * 15 \mathrm{~cm})$.
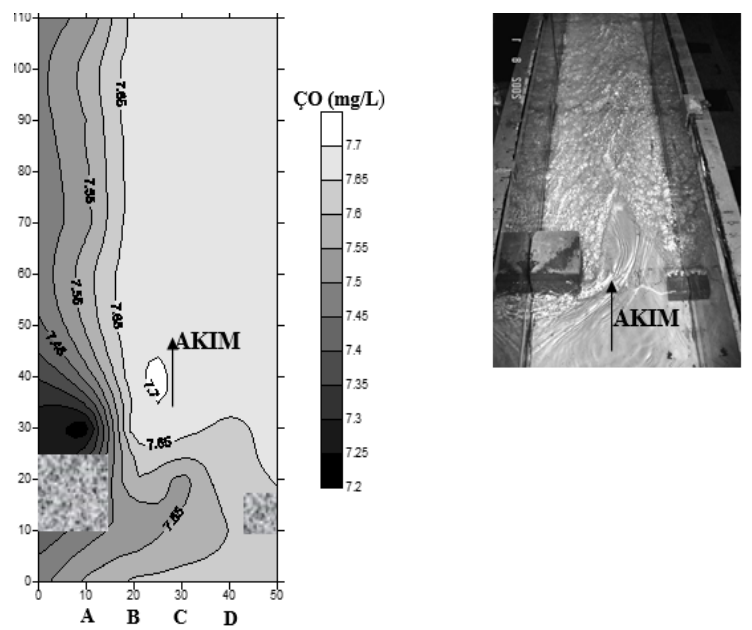

Şekil 4. İki küp düzeneğindeki ÇO dağılımı $(\mathrm{h}=10 \mathrm{~cm}$, Küp boyutları $=15^{*} 15^{*} 15$ ve $\left.6,5 * 6,5 * 6,5 \mathrm{~cm}\right)$.

\section{SONUÇLAR VE ÖNERÍLER}

$\mathrm{Bu}$ çalışmada yapılan deneyler sonucunda elde edilen sonuçlar ve öneriler aşağıdaki şekilde özetlenebilir.

1) İkili kaya parçası düzenekleri tek kaya parçası düzeneklerine göre oksijen kazanımı bakımından hem yerel kazanım hem de toplam verim açısından daha iyi sonuçlar vermiştir.

2) Kaya paçası düzeneklerini aşan su derinliklerinde, oksijen transferi bakımından sistemin verimi düşmektedir.

3) $\mathrm{Su}$ derinliğine bağlı olarak kaya parçası düzeneklerinden sonra oluşan su jeti ve hidrolik sıçramanın şeklinde ve büyüklüğünde farklılıklar olmaktadır. Buna bağlı olarak suya giriş yapan hava kabarcıklarının dağılımı ve büyüklüğü değişmektedir ve ÇO miktarı bu değişimden etkilenmektedir.

4) Kaya parçalarının akım içindeki batıklık oranlarına bağlı olarak akım yapısı değişmektedir. Oksijen transfer verimi bakımından ikili kaya parçası düzeneklerinde akım genelinde 0.33 batıklık oranında, yersel olarak ise 0.66 batıklık oranında daha iyi sonuçlar vermiştir.

5) Kaya parçalarının arkasında oluşan akıma katılmayan bölgelerde DO konsantrasyonu diğer bölgelere göre düşmekte ve DO değeri zamanla değişim göstermektedir.

6) Laboratuvarda yapılan bu ölçümlerin, doğada benzer kaya parçaları düzenekleri içeren bir akarsuda yapılması önerilmektedir.

\section{SEMBOL LISTESİ}

: Oksijen transferinin gerçekleştiği yüzey alanının hacme olan oranı : Gaz-sıvı girişim alanı

: Mansap bölgesindeki oksijen konsantrasyonu

: Sıvı içinde çözünmüş kimyasal madde konsantrasyonu

: Sudaki maksimum çözünmüș oksijen konsantrasyonu

: Türbülans kayma bölgesindeki en büyük hava konsantrasyonu

: Havadaki oksijen konsantrasyonu

: Memba bölgesindeki oksijen konsantrasyonu

: Hidrolik sıçramadan önceki su yüksekliği

: Moleküler difüzyon katsayısı

: Oksijen transfer verimi

: Maksimum oksijen transfer verim katsayısı

: Sıcaklık değişimini gösteren katsayısı

: Froude sayısı

: Su derinliği

: Henry katsayısı

: Kütle transfer katsayısı

: Siv1-kütle transfer katsayısı

: Gazın kütlesi

Gazın havadaki kısmi basıncı

: Oksijen kazanım katsayısı

: Maksimum oksijen kazanım katsayısı

: Reynolds sayısı

: Birim genişlikteki debi

: Hava sıcaklığg

: Referans sıcaklığ 1

: Su sicaklı̆̆ 1

: Ortalama hiz 


\section{KAYNAKLAR}

Artüz, M.L. (2002). Marmara ve Boğazların ekolojisi ve değişimler. SBT Kongresi, İstanbul, Türkiye

Avery, S.T. \& Novak, P. (1978). Oxygen transfer at hydraulic structures. J. Hydr. Div.,ASCE, 104(11), 1521-1540.

Butcher, J.B. \& Covington, S. (1995). Dissolved oxygen analysis with temperature dependence. $J$. of Environmental Engineering., (ASCE), 121, 756-759.

Cokgor S. \& Kucukali, S. (2002). Oxygen transfer around boulders, XXX. IAHR Congress, Thessaloniki, Greece.

Chanson, H. (1994). Hydraulic design of steeped cascades, channels, weirs and spillways. Pregamon Press. Great Britain.

Chanson, H. (1995). Air bubble entrainment in free surface turbulent flows, Experimental investigations. Report No: CH46/95. Department of Civil Engineering, University of Queensland, Australia.

Gulliver, J.S. Wilhelms S.C \& Parkhill, K.L. (1998). Predictive capabilities in oxygen transfer at hydraulic structures. Hydr. Engrg., ASCE, July 1998, 664-671.

Kim J. \& Walters R.W. 2001, Oxygen transfer at low drop weirs. J. Environmental Engrg, ASCE, 127(7), 604610.
Wood, I,R. (1991). Air Entrainment in free-surface flows. A.A Balkema, Rotterdam, Netherlands

Gameson, A.L.H. Vandyke, K.G. \& Ogden, C.G. (1958). The effect of temperature on aeration at weirs. Water and Water Engrg., Nov, 489-492.

Nakasone, H. (1987). Study of aeration at weirs and cascades. J. Envir. Engrg, ASCE, 113, 64-81.

Streeter, V.L., Leutheusser, H.J. \& Alemu, S. (1981). Fluid Mechanics. McGraw-Hill. Singapore.

Thandaweswara, B.S. (1974). Self aerated flow characteristics in developing zones in hydraulic jumps. Ph.D. thesis, Dept. of Civil Engrg, İndian Institute of Science, India.

Van de Donk, J. (1981). Water aeration with plunging jets. Ph. D thesis, TH Delft, Netherlands.

\section{*Corresponding author's:}

Serhat KÜÇÜKALI

Hacettepe Üniversitesi, İnşaat Mühendisliği Bölümü, Beytepe 06800, Ankara, Türkiye.

\E-mail: serhatkucukali@hacettepe.edu.tr

ORCID : https://orcid.org/0000-0002-5867-3270.

Telefon : +90(312) $2977328 / 134$ 